\title{
ESQUEMAS VISUALES Y EMPLAZAMIENTO DE LAS REPRESENTACIONES RUPESTRES DE CAMÉLIDOS DEL LOA SUPERIOR EN TIEMPOS INCAICOS. ¿UNA NUEVA ESTRATEGIA DE INCORPORACIÓN DE ESTE TERRITORIO AL TAWANTINSUYU?
}

\author{
VISUAL OUTLINES AND LOCATION OF CAMELIDS REPRESENTATIONS OF \\ THE UPPER LOA DURING THE INCA TIMES. A NEW STRATEGY OF THE \\ TAWANTINSUYU TO INCORPORATE THIS TERRITORY?
}

Marcela A. Sepúlveda R.*

\begin{abstract}
Se presentan los resultados obtenidos del estudio del arte rupestre adscrito al período Tardío (1.450- 1.540 d.C.), correspondiente a la presencia Inka en la región del Loa Superior. En particular, se analizan las representaciones de camélidos de varios sitios de la cuenca del río Salado, en comparación con algunas del Alto Loa. Este trabajo expone, por un lado, un análisis de las formas anatómicas representadas, definidas como esquemas visuales; y, por otro, algunas observaciones acerca de los emplazamientos de estas manifestaciones rupestres, ligados a distintas actividades de la vida cotidiana. Las características enunciadas para el arte rupestre del período Tardío sugieren una estrecha relación con la expansión incaica en la región. A modo de hipótesis, se amplía una de las interpretaciones anteriores planteadas en la cuenca del río Salado, que considera que el arte rupestre sería utilizado por el Inka como una estrategia de dominación e integración al Tawantinsuyu, ejercida de modo diferencial en el Loa Superior.

Palabras claves: arte rupestre, Inka, período Tardío, el Loa Superior, poder simbólico.
\end{abstract}

I present the results of study rock art dated to the Late period (1.450-1.540 A.D.), which corresponds to the Inka presence in the upper Loa region. Particularly, I analized camelid representations from several sites of the Salado river basin and compared them with representation from the upper Loa river. I present an analysis of anatomical forms defined as visual schemaes, along with observations about the location of the rock art, related to different activities of everyday life. The described characteristics of Late period rock art suggest a tight relation to the Inka expansion in the region. My hypothesis, expands on previous interpretations, for the Salado river basin, which consider that the rock art was used by the Inka as a strategy for domination and integration into Tawantinsuyu, carried out in a different fashion in the upper Loa basin.

Key words: rock art, Inka, Late period, upper Loa area, symbolic power.

Investigaciones realizadas en las últimas décadas (Bauer 1992, 1996; D’Altroy 1992, 2003; Hyslop 1993; Morris 1995) han demostrado la capacidad del Inka para desarrollar una gran variedad de formas de interacción con las poblaciones locales anexadas a su imperio, revelando de paso la existencia de múltiples estrategias diferenciales de conquista.

En el Loa Superior, recientes investigaciones efectuadas particularmente en la cuenca del río Salado, sobre restos arquitectónicos, cerámica y arte rupestre en el Pukara de Turi (Cornejo 1995, 1999; Gallardo y Vilches 1995; Gallardo et al. 1995) y en la localidad de Caspana (Adán 1999;
Adán y Uribe 1999; Uribe et al. 1999; Vilches y Uribe 1999, entre otros), sugieren, al igual que en otros territorios conquistados, que la integración de esta región al Tawantinsuyu sería de orden político, económico, pero esencialmente ideológico, con manifestaciones claras en el plano simbólico.

En este trabajo presentamos nuevos análisis acerca de las manifestaciones rupestres adscritas al período Tardío (ca. 1.450-1.540 d.C.), definido por la presencia Inka en el Loa Superior. Estos nuevos antecedentes permiten profundizar y discutir estudios previos (Gallardo y Vilches 1995, 2001; Berenguer 1999), ampliando hipótesis anteriores de interpretación. Para este efecto se caracterizan

* Recherche sur les Amériques, Université Paris 1- La Sorbonne. marcelaasre@yahoo.com 
las representaciones rupestres de la cuenca del río Salado, para luego compararlas con algunas del Alto Loa. Dicha labor comparativa no ha sido exhaustivamente realizada, hasta ahora, pues ambas regiones han sido investigadas de forma independiente y segregada.

\section{Arte Rupestre y Esquemas Visuales}

Los resultados expuestos requieren precisar ciertas premisas sobre nuestro acercamiento al arte rupestre. Se considera que las representaciones rupestres son una manifestación particular dentro de las evidencias del pasado, pues apelan a un tipo de experiencia específica por parte del artista (o grupo social) quien ejecuta la obra. En palabras de Berger (1975:17): "toda imagen encarna un modo de ver". Se trata de una experiencia visual referida al modo en que un determinado sujeto se enfrenta y representa la realidad que lo rodea. Más específicamente, entendemos que las imágenes rupestres no son una reproducción de la realidad, pues sólo recogen ciertos atributos del referente representado. Como Esquema Visual, la imagen se compone entonces de la elección de ciertos atributos y la relación expresada entre ellos. Cada figura grafica un esquema de la realidad, el cual se adecua a lo que se quiere mostrar (Gombrich 1993:21), codificándolo de tal manera que pueda ser reconocible o legible, y rescatando las características consideradas más importantes tanto para el artista como para el observador (Gombrich 1993:138).

Dicha elección (“codificación”) y su legibilidad son, consecuentemente, no sólo el producto de un proceso de creación individual, sino que deben necesariamente responder a posibles normas determinadas por cierto contexto sociocultural y sociohistórico. La imagen, además de una expresión individual, es también la manifestación de ciertos principios o posibles convenciones sociales. Como representación visual, el arte rupestre se convierte en un elemento activo dentro de la sociedad en que se reproduce, pues manifiesta y comunica cierta forma de percibir y ordenar el mundo (Bourdieu 1977:408).

Más aún, las manifestaciones rupestres poseen además la potencialidad para permanecer, y por lo tanto "hacer visible" la apropiación simbólica de determinado espacio. El emplazamiento escogido para graficar dichas representaciones puede, por ello, también considerarse como un elemento pri- mordial en la organización social y cultural del espacio. Como parte de los sistemas simbólicos, el arte rupestre podría, por ende, perfectamente ser analizado como una estrategia, o medio tecnológico y simbólico para la construcción, mantención y difusión de un determinado orden e ideología (Bourdieu 1977; ver también DeMarrais et al. 1996). Se postula que esto ocurriría en momentos incaicos.

\section{La Cuenca del Río Salado}

Este trabajo engloba tanto sitios de la cuenca del río Salado como del Alto Loa, es decir, del Loa Superior. Sin embargo, se centra en el estudio de los sitios de la cuenca del río Salado que forma parte de un conjunto de varios ríos (el Caspana, el Toconce y el Curte, entre otros), que fluyen por profundas quebradas que interrumpen un extenso plano rocoso de origen volcánico, ubicado entre los 2.000 y los $3.800 \mathrm{msm}$ (Gallardo 2001).

Más particularmente, los sitios con arte rupestre se emplazan en la parte alta de la cuenca del río Salado, es decir, en las zonas definidas como: quebradas intermedias (entre los 3.000 a $3.200 \mathrm{msm}$ ), donde se encuentran las localidades de Turi y Ayquina, y quebradas altas (3.200 a $3.600 \mathrm{msm}$ ), con la presencia de las localidades de Cupo, Caspana y Toconce (Gallardo et al. 1999).

En la actualidad, si bien se observa un panorama bastante árido en esta zona precordillerana, en el pasado el agua proveniente de los deshielos cordilleranos, de los manantiales y de los cursos subterráneos que afloran a veces como río debieron permitir la formación de un paisaje mucho más rico en flora y fauna, destacando la formación de amplias vegas de forrajeo.

El período Tardío (ca. 1.450-1.535 d.C.) en la cuenca alta del río Salado se define por la presencia Inka, posiblemente atraído por las riquezas mineras de la región (Aldunate 2001; Cornejo 1995; Salazar et al. 2001; Salazar 2002). Las formas de incorporación de esta región al Tawantinsuyu, así como el tipo de interacción del Inka con las poblaciones locales, son, a pesar del reconocido interés, aún temas discutidos (Cornejo 1995). No obstante, basados en las evidencias recuperadas se reconoce la instauración de un nuevo orden primero espacial, simbólico y religioso (Salazar 2002; Uribe et al. 1999), producto de una nueva ideología (Adán y Uribe 1999; Cornejo 1995; Gallardo et al. 1995). 
Con ella se establece la coexistencia de elementos locales e inkas, sin una imposición violenta de lo incaico. Más bien, se visualiza una conversión ideológica paulatina, de influencia indirecta o mediatizada y posiblemente de origen altiplánico (Cornejo 1995; Llagostera 1976).

\section{Estudios Previos sobre Arte Rupestre Incaico en la Cuenca del Río Salado}

En esta región, el reconocimiento de un arte rupestre incaico es bastante reciente, iniciándose con los estudios realizados en el Pukara de Turi, en la mitad de la década de 1990 (Gallardo y Vilches 1995). Basados en las representaciones de camélidos, Gallardo y Vilches identifican un grupo 1 , caracterizando así figuras obtenidas mediante trazado lineal, con tendencia a formar ángulos rectos en las uniones cabeza-cuello, cuello-cuerpo y cuerpo-extremidades. Este grupo es definido como contemporáneo al Inka, en base a su semejanza con las figurinas de metales recuperadas en los santuarios de altura y los diseños presentes sobre textiles inkas (Gallardo y Vilches 1995:26).

Actualmente, este tipo de representaciones conforma lo que ha sido denominado Estilo Quebrada Seca (Gallardo et al. 1999). Se caracteriza por figuras generalmente grabadas, técnicamente simples, realizadas mediante un trazo rectilíneo, de surco fino y ancho regular. Si bien en su mayoría este estilo identifica figuras de camélidos esquemáticos, de rasgos ortogonales, ahora se le integran algunas escasas representaciones antropomorfas igualmente simples, además de los grabados en bajorrelieve conocidos como "maquetas" (Castro y Gallardo 1995-96). Su emplazamiento en distintos espacios (abiertos y cerrados), sobre paredes de quebrada o sobre bloques, y su asociación con diferentes contextos arqueológicos sugiere una estrecha relación con las diversas actividades de la vida cotidiana (Gallardo et al. 1999:74).

Tras su definición, nuevos estudios realizados en la localidad de Caspana integran a este Estilo Quebrada Seca otras formas de representaciones esquemáticas de camélidos, definidas por cuerpos más anchos, o realizadas mediante pintura (Vilches y Uribe 1999), y que ya habían sido observadas en el Pukara de Turi (Gallardo y Vilches 1995). Su análisis en sitios no habitacionales permite a Vilches y Uribe suponer que todas estas representaciones serían el resultado de la expansión del
Tawantinsuyu en la cuenca del río Salado, siendo utilizadas como una marca territorial o en un "emblema del Inka" (Vilches 1999; Vilches y Uribe 1999). Esta interpretación apunta a que la representación de camélidos esquemáticos por "sus propiedades altamente estandarizadas" es identificable "a lo largo del imperio en diferentes dominios de la cultura material" (Vilches y Uribe 1999:83, ver también Hyslop 1993: 337). Además de la comparación de estas figuras con diseños similares presentes sobre otros tipos de soportes materiales como textiles, cesterías o cerámicas, su naturaleza incaica es también definida por su presencia en sitios inkas, y su ausencia en los sitios de sustrato local (Vilches y Uribe 1999).

Finalmente, Gallardo y Vilches (2001) presentan una interpretación general del arte rupestre incaico en la cuenca del río Salado, ahondando en la relación Inka-población local. Reconocen que su factura simple sin duda permitió su masiva reproducción y su amplia distribución espacial, dada su presencia también en el noroeste argentino (ver Aschero 2000). Plantean además, que dichas representaciones serían realizadas por la población local, como una forma de intervención del Inka en los ámbitos simbólico y social locales, estableciendo un cierto equilibrio entre la imposición de un poder central y cierta libertad de las comunidades locales para realizar dichas manifestaciones. Esta relación sería producto de la interacción promovida por posibles funcionarios incaicos para así maximizar la ganancia sobre el trabajo de la población local (Gallardo y Vilches 2001).

\section{Análisis de las Representaciones de Camélidos}

Con el fin de ampliar los resultados obtenidos por los estudios recién resumidos, en esta oportunidad se consideraron las manifestaciones de 7 sitios de la cuenca del río Salado: Pukara de Turi (Gallardo y Vilches 1995; Vilches 1999), Quebrada Seca (Gallardo et al. 1999), Ayquina (Gallardo et al. 1990), Incahuasi Inka, Cueva del Diablo, El Mirador y La Cruz (los cuatro últimos sitios publicados también en Vilches y Uribe 1999). A éstas se agregan las de 10 sitios del Alto Loa: SBa-41 (Cáceres y Berenguer 1996), 103, 110, 119, 142, 144, 266 y Alero Laguna Este, Paskana de Taira, y Alero Zurita (Berenguer 1999; Berenguer et al. 1986; Berenguer 2002; Horta 2001), (distribución de los sitios ver Figura 1; para la descripción gene- 
ral de cada sitio, ver Tabla 1). Todos ellos fueron escogidos por la presencia de contextos o fechas del período Tardío; o bien por comparación iconográfica de ciertos paneles sin asociaciones arqueológicas, con sitios bien contextualizados.

En ambas áreas no fue posible precisar la cantidad exacta de figuras en razón del tipo de información utilizada. Mientras para los sitios de la cuenca del río Salado se tuvo acceso al registro completo de las manifestaciones rupestres; para el Alto Loa se utilizó el material publicado por otros investigadores (Berenguer et al. 1986; Cáceres y Berenguer 1996; Berenguer 1999; Horta 2001). Sin embargo, la cuantificación no resulta ser un problema para el análisis acá descrito. Lo importante era distinguir las formas anatómicas de los camélidos representados en cada panel o sitio (Figura 2).

Inicialmente, la observación de las representaciones de camélidos esquemáticos de los sitios de la cuenca del río Salado, adscritos al período Tardío (ver Tabla 2), permitió identificar tres esquemas dentro de la tradición esquemática u ortogonal (ver ilustración de cada esquema en dibujos y Tabla 2).

Un esquema la, consistente en camélidos grabados o pintados, rectilíneos de trazo fino y regu- lar, de 2 patas y una oreja, poniendo énfasis en la representación de un animal sin volumen y representado en un solo plano (ver paneles de La Cruz y del Pukara de Turi en Figura 2). Este caso forma parte de lo que ha sido definido como Estilo Quebrada Seca (Gallardo et al. 1999). A este esquema se suma un caso único, hasta ahora, del sitio Alero Laguna Este, en el Alto Loa (foto de la página 36, Berenguer 1999) donde estos camélidos son representados con 4 patas. Este caso, aunque único, define el esquema $1 b$.

Un esquema 2, caracterizado por camélidos grabados o pintados de cuerpos rectangulares, es decir, con un interés por denotar más el volumen del cuerpo. En este esquema identificamos dos variables: $2 a$, en relación a camélidos de cuerpo rectangular y dos patas; y $2 b$, agrupando camélidos de cuerpo rectangular pero de 4 patas (ver ejemplo en panel de Cueva del Diablo, Figura 2). Ambos se distinguen por el hecho de que si bien muestran intención por destacar el volumen del cuerpo, no coinciden en la representación de la dimensionalidad. En el caso 2a, el animal se dibuja en un plano; mientras el $2 \mathrm{~b}$ representa dos planos, con el desdoblamiento de las patas dibujadas como traídas a un mismo plano.

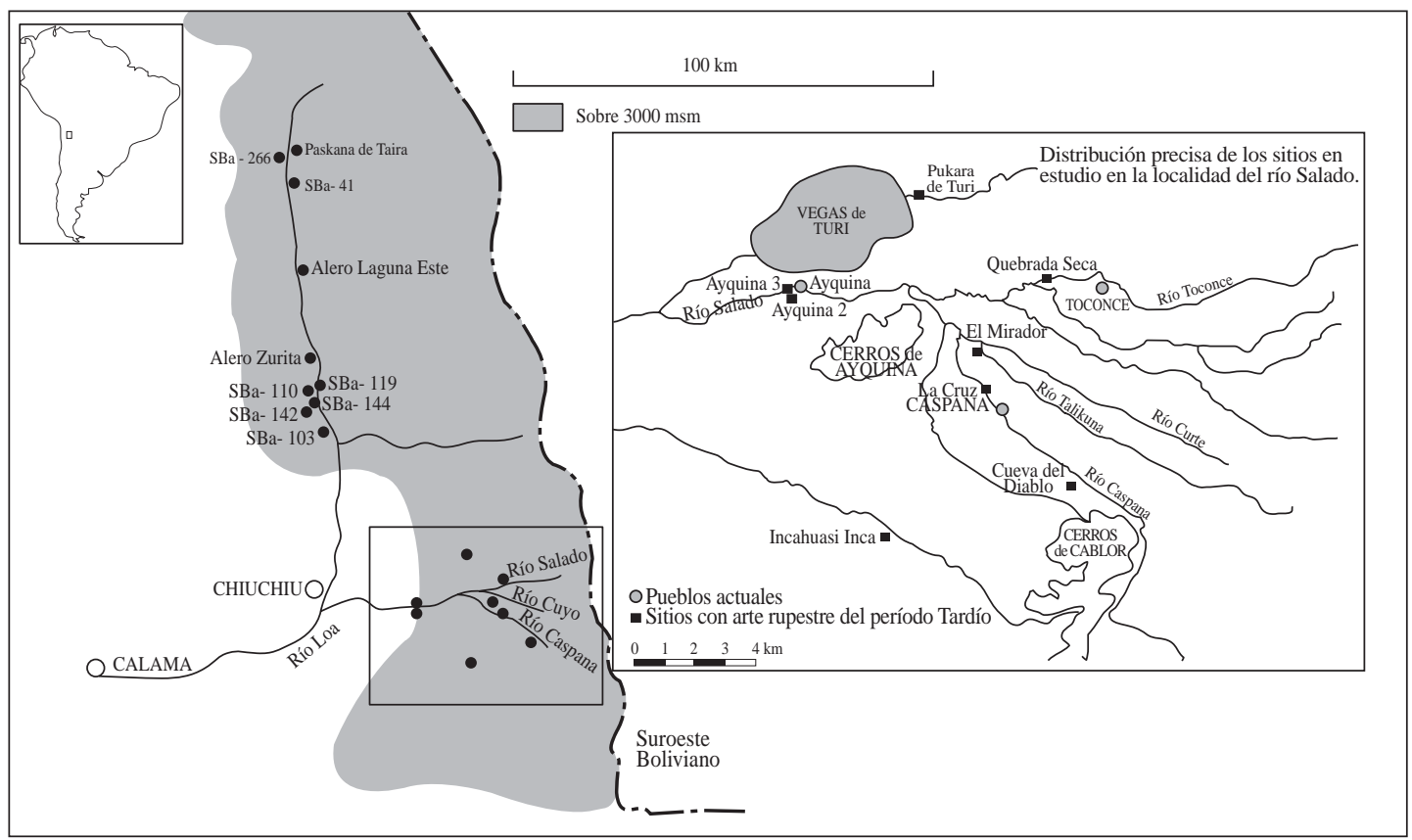

Figura 1. Distribución de sitios con arte rupestre del período Tardío en el Loa Superior. Distribution of rock art sites of the Late Period in the upper Loa. 
Tabla 1. Descripción de los sitios del Loa Superior analizados.

Distribution of rock art sites analyzed in the upper Loa basin.

\begin{tabular}{|c|c|c|c|c|c|c|}
\hline \multirow{8}{*}{$\begin{array}{c}\text { RÍO } \\
\text { SALADO }\end{array}$} & Sitio & Técnica & $\begin{array}{l}\text { Emplazamiento y } \\
\text { Asociaciones }\end{array}$ & $\begin{array}{l}\text { Adscripción } \\
\text { cronológica }\end{array}$ & Fechas & Referencias \\
\hline & Pukara de Turi & Grabado & $\begin{array}{c}\text { - bloques rocosos } \\
\text { - asentamiento habitacional }\end{array}$ & PIT- TARDÍO & $900-1.650$ d.C. & $\begin{array}{c}\text { Aldunate 1993; } \\
\text { Gallardo y } \\
\text { Vilches } 1995\end{array}$ \\
\hline & Ayquina & Pintura & $\begin{array}{c}\text { - pared de la quebrada } \\
\text { - senderos }\end{array}$ & PIT- TARDÍO & - & $\begin{array}{c}\text { Gallardo et al. } \\
\text { 1990; } \\
\text { Sepúlveda } \\
2002\end{array}$ \\
\hline & Incahuasi Inca & Pintura & $\begin{array}{l}\text { - interior de una collca } \\
\text { - asentamiento habitacional }\end{array}$ & TARDÍO & $\begin{array}{l}1.440 \mathrm{y} \\
1.480 \mathrm{~d} . \mathrm{C} .\end{array}$ & $\begin{array}{l}\text { Vilches y } \\
\text { Uribe } 1999\end{array}$ \\
\hline & Quebrada Seca & Grabado & $\begin{array}{l}\text { - pared de la quebrada } \\
\text { - senderos }\end{array}$ & TARDÍO & - & $\begin{array}{l}\text { Gallardo et al. } \\
1999 ; \\
\text { Sepúlveda } \\
2002\end{array}$ \\
\hline & La Cruz & Grabado & $\begin{array}{l}\text { - bloque rocoso } \\
\text { - senderos }\end{array}$ & TARDÍO & - & $\begin{array}{l}\text { Vilches y } \\
\text { Uribe } 1999\end{array}$ \\
\hline & El Mirador & Grabado & $\begin{array}{c}\text { - pared de la quebrada } \\
\text { - asentamiento habitacional }\end{array}$ & $\begin{array}{l}\text { TARDÍO } \\
\text { PIT (i?)- }\end{array}$ & - & $\begin{array}{l}\text { Vilches y } \\
\text { Uribe } 1999\end{array}$ \\
\hline & $\begin{array}{l}\text { Cueva del } \\
\text { Diablo }\end{array}$ & Pintura & $\begin{array}{c}\text { - abrigo rocoso } \\
- \text { sin contexto arqueológico }\end{array}$ & TARDÍO & - & $\begin{array}{l}\text { Vilches y } \\
\text { Uribe } 1999\end{array}$ \\
\hline \multirow{10}{*}{$\begin{array}{l}\text { ALTO } \\
\text { LOA }\end{array}$} & SBa-41 & Grabado & $\begin{array}{c}\text { - bloques rocosos } \\
\text { - asentamiento habitacional }\end{array}$ & PIT- TARDÍO & $\begin{array}{c}940- \\
1.440 \pm 60 \text { d.C. }\end{array}$ & $\begin{array}{l}\text { Cáceres y } \\
\text { Berenguer } \\
1996\end{array}$ \\
\hline & SBa-103 & Grabado & $\begin{array}{c}\text { - bloques rocosos } \\
\text { - asentamiento habitacional }\end{array}$ & TARDÍO & $\begin{array}{c}1.220 \pm 70- \\
1.410 \pm 60 \text { d.C. }\end{array}$ & $\begin{array}{l}\text { Cáceres y } \\
\text { Berenguer } \\
1996\end{array}$ \\
\hline & SBa-110 & $\begin{array}{l}\text { Pintura y } \\
\text { Grabado }\end{array}$ & - alero & $\begin{array}{l}\text { PIT (i?)- } \\
\text { TARDÍO }\end{array}$ & $\begin{array}{l}1.550 \pm 50 \\
\text { d.C. }\end{array}$ & $\begin{array}{l}\text { Berenguer } \\
\text { et al. 1985: } \\
\text { Berenguer } \\
\quad 1999\end{array}$ \\
\hline & SBa-119 & Grabado & $\begin{array}{c}\text { - pared quebrada } \\
\text { - cerca de asentamiento } \\
\text { habitacional }\end{array}$ & TARDÍO & $\begin{array}{l}1.310-1.480 \\
\text { d.C. }\end{array}$ & $\begin{array}{l}\text { Berenguer } \\
\text { et al. 1985; } \\
\text { Berenguer } \\
\quad 1999\end{array}$ \\
\hline & SBa-142 & Grabado & $\begin{array}{c}\text { - pared de la quebrada } \\
\text { - sin contexto arqueológico }\end{array}$ & TARDÍO & - & $\begin{array}{l}\text { Berenguer } \\
\text { et al. } 1985\end{array}$ \\
\hline & SBa-144 & Grabado & $\begin{array}{c}\text { - bloques rocosos } \\
\text { - abrigo rocoso cerrado por } \\
\text { muro pircado }\end{array}$ & TARDÍO & - & $\begin{array}{l}\text { Berenguer } \\
\text { et al. 1985; } \\
\text { Berenguer } \\
\quad 1999\end{array}$ \\
\hline & SBa-266 & Grabado & $\begin{array}{l}\text { - bloque rocoso } \\
\text { - sendero }\end{array}$ & TARDÍO & - & $\begin{array}{l}\text { Berenguer } \\
1999\end{array}$ \\
\hline & $\begin{array}{l}\text { Alero Laguna } \\
\text { Este }\end{array}$ & Grabado & $\begin{array}{l}\text { - alero } \\
\text { - espacio cerrado por muro } \\
\text { pircado; usado posiblemente } \\
\text { como asentamiento, presencia } \\
\text { de corrales }\end{array}$ & $\begin{array}{l}\text { PIT ( }(\text { ? )- } \\
\text { TARDÍO }\end{array}$ & \pm 1.030 d.C. & $\begin{array}{c}\text { Rivera y } \\
\text { Marinov } 2001\end{array}$ \\
\hline & $\begin{array}{l}\text { Paskana de } \\
\text { Taira }\end{array}$ & Grabado & $\begin{array}{l}\text { - bloque rocoso } \\
\text { - sendero }\end{array}$ & $\begin{array}{l}\text { PIT (i?)- } \\
\text { TARDÍO }\end{array}$ & - & $\begin{array}{l}\text { Berenguer } \\
1999\end{array}$ \\
\hline & Alero Zurita & Pintura & $\begin{array}{l}\text { - alero } \\
\text { - sendero }\end{array}$ & $\begin{array}{l}\text { PIT (i?)- } \\
\text { TARDÍO }\end{array}$ & - & $\begin{array}{l}\text { Berenguer } \\
1999\end{array}$ \\
\hline
\end{tabular}




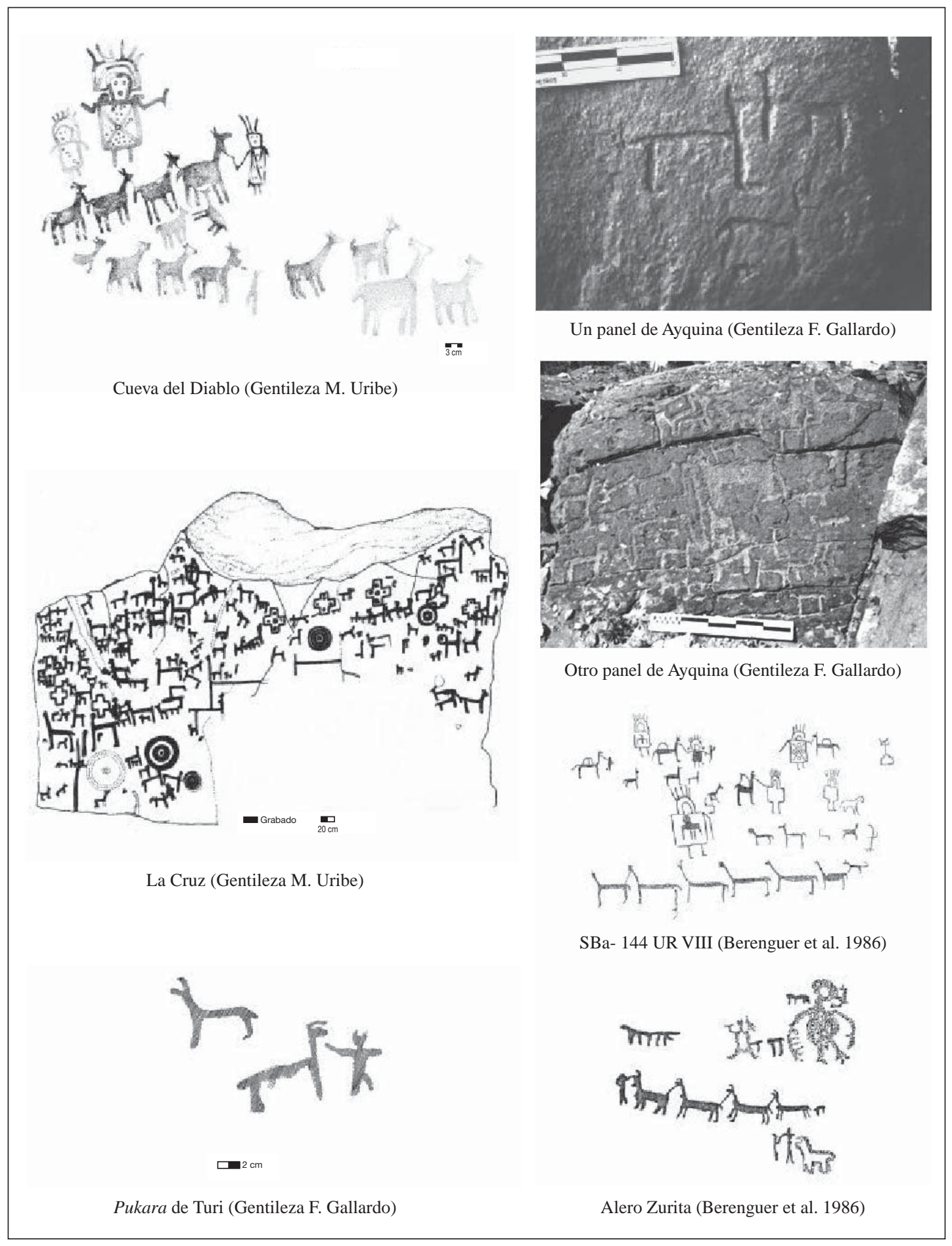

Figura 2. Ejemplos de paneles rupestres del período Tardío.

Examples of rock art panels of the Late Period. 
Tabla 2. Distribución de esquemas visuales identificados en los diferentes sitios del Loa Superior. Distribution of visual schemes identified in various sites of the upper Loa basin.

\begin{tabular}{|c|c|c|c|c|c|}
\hline \multirow[b]{2}{*}{ Dibujo } & \multirow[b]{2}{*}{ Sitio } & Esquema 1 & & a 2a & Esquema 2b \\
\hline & & $\int_{-\infty}^{6}$ & Pukara de Turi & Ayquina & Cueva del Diablo \\
\hline $\begin{array}{c}\text { RÍO } \\
\text { SALADO }\end{array}$ & $\begin{array}{l}\text { Pukara de Turi } \\
\text { Ayquina } \\
\text { Incahuasi Inca } \\
\text { Quebrada Seca } \\
\text { La Cruz } \\
\text { El Mirador } \\
\text { Cueva del Diablo }\end{array}$ & $\begin{array}{l}X \\
X \\
X \\
X \\
X \\
X\end{array}$ & & & $\mathrm{X}$ \\
\hline $\begin{array}{l}\text { ALTO } \\
\text { LOA }\end{array}$ & $\begin{array}{l}\text { SBa- 41 } \\
\text { SBa- } 103 \\
\text { SBa- } 110 \\
\text { SBa- } 119 \\
\text { SBa- } 142 \\
\text { SBa- } 144 \\
\text { SBa- 266 } \\
\text { Alero Laguna Este } \\
\text { Paskana de Taira } \\
\text { Alero Zurita }\end{array}$ & $\begin{array}{l}X \\
X \\
\\
X \\
X\end{array}$ & & & $\begin{array}{l}X \\
X\end{array}$ \\
\hline
\end{tabular}

(Los dibujos del Pukara de Turi y la foto de Ayquina fueron amablemente facilitados por Francisco Gallardo; mientras que el dibujo de Cueva del Diablo fue gentilmente prestado por Mauricio Uribe).

En el Alto Loa, si bien Berenguer (2002:556) distingue camélidos, acá definidos como esquemas 1 y 2 , para él en conjunto conforman el denominado Estilo Santa Bárbara I.

Definidos en base a los sitios de la cuenca del río Salado, la Tabla 2 muestra la distribución de cada esquema en todos los sitios del Loa Superior considerados en este análisis. En dicha tabla se reconoce el predominio del esquema 1 tanto en la cuenca del río Salado como en Alto Loa, convirtiéndose en una forma de representación muy popular en sitios de la prehistoria tardía de la región. Sin embargo, no coincidimos con Vilches y Uribe (1999), pues no se trata de sitios asociados estricta y exclusivamente a ocupaciones incaicas (Pukara de Turi, Incahuasi Inka), como lo demuestra la gran cantidad de sitios pequeños en aleros (ver Tabla 1). Coincidimos con Berenguer (2002) que la localización de sitios como El Mirador, Cueva del Diablo, en la órbita del sitio minero incaico de
Cerro Verde, no es argumento suficiente para definirlo como Inka.

De acuerdo a la Tabla 2, la mayor diferencia radica en los esquemas $2 a$ y $2 b$, menos populares que el esquema 1 en los sitios del Loa Superior, pero igualmente presentes en las dos regiones analizadas. La presencia de camélidos de cuerpo rectangular parece ser más recurrente en el Alto Loa, dada su presencia en varios sitios. En la cuenca del río Salado, en cambio, sólo se registra en un panel del sitio Cueva del Diablo. Se trata de varios camélidos del esquema $2 b$, con la particularidad de estar asociados a figuras antropomorfas vestidas con camisas rectangulares decoradas y tocados radiados (Vilches y Uribe 1999, ver panel en Figura 2).

Varias representaciones de camélidos de Ayquina corresponden también al esquema 2 (ver ilustraciones en Gallardo et al. 1990 o Gallardo et al. 1999, ver Figura 2). Sin embargo, la presencia de 
algunas figuras de jinetes sobre animales de 2 patas, de cuerpo rectangular semejantes a algunas representaciones del esquema 2, pone en duda dicha interpretación. Ciertas representaciones interpretadas como camélidos podrían, en realidad, corresponder a figuras de caballos. Atributos como la cola generalmente muy larga en los caballos montados, mientras en los camélidos es muy corta y pequeña, así como la proporción cuerpo-cuello del animal podrían permitir distinguirlos, aunque este planteamiento debiera ser analizado detalladamente.

De acuerdo a estos resultados, existirían diferencias formales entre la cuenca del río Salado y el Alto Loa. Mientras en la primera zona predominan los camélidos del esquema 1, con excepción del sitio Cueva del Diablo (Figura 2), en el Alto Loa hay una mayor diversidad de representaciones, aunque son más recurrentes camélidos de cuerpo rectangular, sean de 2 ó 4 patas (ver Figura 2).

\section{Figuras Antropomorfas Asociadas}

Aunque este trabajo se centra en las representaciones de camélidos, es necesario hacer algunas observaciones sobre las escasas figuras antropomorfas presentes en varios paneles de ambas áreas. Estas representaciones muestran dos situaciones bien diferentes.

Un primer grupo reúne figuras antropomorfas de tamaño más pequeño que los camélidos a los que se relacionan; además de poco detalle de ornamentación -generalmente sólo un tocado radiado o en "forma de tumi"-. Estas imágenes se observan en paneles de los sitios de La Cruz, del Pukara de Turi, de Ayquina, de SBa-41 (Cáceres y Berenguer 1996), de Alero Zurita (Figura 2) y de la Paskana de Taira (Berenguer 1999: 37).

Un segundo grupo distingue algunas representaciones más elaboradas, vestidas con camisas generalmente decoradas, además de grandes tocados radiados, como en los sitios de Cueva del Diablo (Figura 2) y SBa- 110 (Berenguer 1999:45). En el Alto Loa, estas figuras han sido interpretadas como "mensajeros del Inca" (Berenguer 1999), formando parte de su denominado Estilo Santa Bárbara II (Berenguer 2002:560). La semejanza de las camisas y sus decoraciones con textiles incaicos apoya dicha hipótesis. Sin embargo, coincidiendo con Berenguer (1999) se observan diferencias forma- les en las camisas representadas. Mientras en Cueva del Diablo éstas son rectangulares (atacameñas), en SBa-110 son trapezoidales (tarapaqueñas) o en forma-escudo (del noroeste argentino). Dicha distinción podría sugerir que ambos paneles no fueron realizados por artistas de una misma entidad sociocultural; que dichas representaciones no ilustran el mismo tipo de personas; o bien que fueron ejecutados en distintos momentos (período Intermedio tardío para Cueva del Diablo y Tardío para SBa- 110 -Berenguer 1999, 2002).

En esta etapa de análisis resolver dichas interrogantes resulta aún muy ambicioso. De este breve reconocimiento, se desprende que aunque existen dos tipos de figuras antropomorfas asociadas a camélidos de tradición esquemática, éstas se ven notablemente disminuidas en cantidad y tamaño (salvo para el panel de SBa- 110). En el universo de figuras analizadas, durante el período Tardío, los camélidos se vuelven los protagonistas de las representaciones rupestres.

\section{Emplazamientos de los Camélidos de Tradición Esquemática en el Loa Superior}

En relación al emplazamiento de los sitios analizados también se observan diferencias entre la cuenca del río Salado y el Alto Loa. En la Figura 1, la distribución de los sitios muestra que mientras en la cuenca del río Salado las representaciones aparecen indistintamente en diferentes quebradas, en el Alto Loa, en cambio, éstas se concentran alrededor de la localidad de Santa Bárbara. Hasta ahora, no se visualizan camélidos de tradición esquemática en los otros sectores del Alto Loa, ni en asociación a las estructuras Inkas como Cerro Colorado, Incahuasi (Berenguer 1994). Al respecto, Horta (2001) plantea que la elección de Santa Bárbara estaría en relación con la presencia de un ensanchamiento del cañón del río Loa en ese sector, donde se ve favorecido el emplazamiento de los asentamientos de viviendas aglutinadas y el desarrollo de actividades de pastoreo y horticultura, a partir del período Medio (Horta 2001:89).

Otra diferencia entre las dos áreas investigadas se refiere a la ubicación de las manifestaciones rupestres. En la cuenca del río Salado los sitios analizados se emplazan generalmente en sitios abiertos y/o habitacionales. En el Alto Loa, en cambio, se encuentran casi en su mayoría al interior de aleros, es decir, en espacios más reducidos. 
En resumen, en el Loa Superior, en general, salvo en los casos del Pukara de Turi, Incahuasi Inka y SBa- 41, la mayoría de los sitios con representaciones rupestres de la tradición esquemática son de espacio restringido, de ocupación efímera o de tránsito.

\section{Características del Arte Rupestre en Tiempos Incaicos}

Coincidiendo con los resultados obtenidos por otros autores (Gallardo et al. 1999; Vilches y Uribe 1999; Gallardo y Vilches 2001), pareciera que en el período Tardío se populariza una tradición rupestre esquemática, evidenciada en el Estilo Quebrada Seca (esquema 1) y la gran variabilidad de esquemas visuales descritos anteriormente.

En dicha tradición, a pesar de las diferencias formales y visuales identificadas como esquemas en este trabajo, se reconocen ciertas normas compartidas como: el ser de tamaño relativamente pequeño, no superior a los $20 \mathrm{~cm}$; y el predominio cuantitativo y cualitativo de la figura del camélido por sobre las antropomorfas, reducidas en tamaño y con menos detalles de ornamentación que en períodos anteriores (Montt 2000). En el período Tardío, el camélido se convierte en el "protagonista" de las representaciones rupestres.

La composición de los paneles muestra figuras generalmente representadas en forma aislada (Pukara de Turi), o a lo más en relación a otros pocos camélidos o figuras antropomorfas como en los sitios de Incahuasi Inka, Ayquina, Cueva del Diablo (Figura 2), La Cruz (Figura 2), Santa Bárbara y del Alto Loa en general (Berenguer 1999). En estos últimos conjuntos de sitios y en Cueva del Diablo se reconoce la particular representación de escenas ligadas al tráfico de caravanas (Berenguer 2002). Sólo en los sitios de Quebrada Seca (Gallardo et al. 1999) y La Cruz (Figura 2) se observan grandes paneles caracterizados por la presencia de una multitud de camélidos en desorden, sin alineamiento particular.

Respecto de sus emplazamientos y asociaciones contextuales, se observa que efectivamente parecen marcar diferentes esferas de la vida cotidiana (Gallardo y Vilches 2001). Las representaciones tardías se asocian a sitios habitacionales o bien a espacios relacionados con actividades productivas (agricultura, pastoreo y caravaneo). No se observan, hasta ahora, en sitios funerarios o aso- ciados directamente a la minería, por ejemplo, aunque se encuentren en la "órbita" de espacios vinculados a la explotación minera (Vilches y Uribe 1999). Las representaciones esquemáticas, analizadas en este trabajo, parecieran asociarse más a sitios con ocupaciones efímeras, más que a sitios habitacionales.

Los resultados de este estudio permiten distinguir dos conjuntos de representaciones: el esquema 1 y una multitud de variantes identificadas como esquema 2. A diferencia de lo planteado por Vilches y Uribe (1999) y coincidiendo con Gallardo et al. (1999), sugerimos que el Estilo Quebrada Seca se identifica con la forma más estandarizada y simple de los camélidos rectilíneos, definidos acá como esquema 1. El esquema 2, si bien forma parte de la misma tradición esquemática, muestra menos ímpetu en seguir un patrón estricto de representación visual, pudiéndose combinar los atributos del referente real siguiendo pautas variables: cuerpo lineal con 4 patas (animal sin volumen pero con las patas dibujadas utilizando ciertas reglas de dimensionalidad), o cuerpo rectangular o areal con 2 patas (haciendo énfasis en el volumen del cuerpo, pero con un animal representado en un plano), entre otros.

A modo de hipótesis, se sugiere que el Estilo Quebrada Seca podría corresponder a la forma Inka, debido a su representación en diversos soportes (Vilches 1999), y particularmente en relación a la forma de camélido representado en un panel cercano al sitio de Pisaq, que podría relacionarse con el Inka (Flores Ochoa et al. 1995). Así, se coincidiría con Adán (1999:31) quien plantea que "una materialidad para el dominio debe ser reproducible, distinguible y estilísticamente simple" para su masiva reproducción y fácil reconocimiento. El Inka "sobre representa a fuerza de síntesis" (Adán 1999), y en el arte rupestre la realización de camélidos esquemáticos reducidos a su máxima expresión de simpleza cumpliría con dicho planteamiento.

Frente a esta forma estandarizada, la más grande variedad de formas podría entonces representar adaptaciones locales de ese icono (Gallardo y Vilches 2001); sin perjuicio que su realización haya ocurrido antes de la llegada efectiva del Inka al Loa Superior, durante el período Intermedio tardío. Realizadas bajo normas variables, la adopción de una nueva forma y su reproducción variable, podría también sugerir posibles nuevos significados. 
En este caso, planteamos que al igual que en las demás manifestaciones materiales inkas se establece un diálogo permeable entre una forma propia del inka pero retomada por las poblaciones locales quienes retraducen el significado de este icono particular (esquema l) y en su propio provecho.

Esta adaptación y "resignificado" ocurriría de manera diferencial en distintas regiones de Atacama, lo cual explicaría las diferencias observadas entre las representaciones esquemáticas de la cuenca del río Salado con las del Alto Loa (Berenguer et al. 1986; Berenguer 1999; Cáceres y Berenguer 1996). Dicho reconocimiento reflejaría no sólo un proceso de adopción de un icono particular por parte de las comunidades locales, sino que evidenciaría también una aproximación diferencial del Inka a las distintas áreas del Loa Superior.

Mientras en la cuenca del río Salado se aprecia la reproducción mayoritaria de una forma más incaica (esquema 1), en composiciones de figuras aisladas o dispuestas masivamente en forma desordenada (agregado de camélidos en forma desordenada, como en el panel del sitio La Cruz - Figura 2), en el Alto Loa se aprecia una mayor diversidad de representaciones de camélidos, en composiciones y sitios mayormente vinculados a la movilidad caravanera. Así, mientras en la cuenca del río Salado se pone mayor énfasis en la figura del camélido, con un significado por ahora desconocido, en el Alto Loa se acentúa la representación de la actividad de intercambio o del desplazamiento de caravanas. Dicha diferencia podría estar expresando una función diferencial de estas dos regiones durante el período Tardío, y por ende un interés distinto por parte del Inka. Un análisis espacial preciso de la presencia inka en el Loa Superior y de la relación entre sitios inkas y locales podría precisar la naturaleza de su interacción, así como el interés específico por parte del Tawantinsuyu en estas dos regiones (proyectos Fondecyt en curso, a cargo de José Berenguer en el Alto Loa y Victoria Castro en la cuenca del río Salado).

Sin embargo, debe precisarse que la variabilidad reconocida puede también ser interpretada de otra forma, ligada a un factor temporal. Camélidos de cuerpo lineal y 2 patas aparecen montados en tiempos coloniales tempranos (Aschero 2000:29; Berenguer 1999:47 ), lo que podría justificar lo tardío del esquema 1 y por ende del Estilo Quebrada Seca. Los casos observados en Ayquina de anima- les de cuerpo rectangular con 4 patas que aparecen montados más bien podrían ser representaciones de caballos en tiempos coloniales avanzados.

$\mathrm{Al}$ opuesto, las representaciones de SBa- 41, en el Alto Loa (Cáceres y Berenguer 1996) sugieren una realización más temprana, durante el período Intermedio tardío (850-1.450 d.C.), dadas las fechas por TL y C14 obtenidas en el sitio, ubicadas entre el 940 y 1.425 d.C (Berenguer 2002: 575). Si asumimos que la tradición esquemática es difundida en tiempos incaicos, la presencia de camélidos de los esquemas 2 podría ser producto de la llegada anticipada de ciertas ideas acerca de la forma como hacer las cosas, previa al efectivo arribo de poblaciones inkas en el Loa Superior (Cornejo 1999; Llagostera 1976).

Aunque estos problemas aún queden sin resolver, lo importante es notar que hacia el período Tardío se instaura una tradición rupestre de forma esquemática, ortogonal y relativamente estandarizada. Se trata de una actividad realizada por las comunidades del Loa Superior en tiempos incaicos (ver Gallardo y Vilches 2001), que retoma un patrón estético inka, pero bajo normas locales y variables.

\section{Comentarios Finales}

La ocupación inka de la región del Loa Superior si bien no evidencia, hasta ahora, grandes centros administrativos como los observados, por ejemplo, en el noroeste argentino o en la sierra del Perú, no parece ser menos eficiente o menos significativa. La relación establecida con las poblaciones locales, posiblemente a través de los jefes de las comunidades regionales (Ayala et al. 1999; Salazar 2001), a nivel ideológico con claras expresiones simbólicas fue lo suficientemente efectiva como para lograr establecer un dominio político y económico sobre la producción y la mano de obra local.

El arte rupestre, tal cual ha sido analizado en este trabajo, aunque con las evidentes restricciones debidas esencialmente al problema cronológico y contextual, podría en el período Tardío jugar un importante rol en las estrategias desplegadas por el Inka como mecanismo de integración del Loa Superior al Tawantinsuyu.

Con el Inka en la cuenca del río Salado y probablemente en el Alto Loa habría ocurrido la instauración de una nueva forma de representación, 
reflejo de un posible nuevo orden ideológico, usando quizás la visibilidad y las formas de sus manifestaciones como uno de sus mecanismos más efectivos (Adán 1999). Este cambio se expresaría también en una reestructuración de las formas de expresión, pero en un diálogo con las poblaciones locales, quienes generan una respuesta particular a esa influencia.

La imagen del camélido se transforma en una especie de icono de forma estandarizada y reconocible (Estilo Quebrada Seca), siendo con ello plenamente significativo a nivel simbólico. En el Loa Superior, este tipo de representaciones no logra su eficacia por su tamaño, o su visibilidad a grandes distancias, sino por su forma, entrando a formar parte de distintos ámbitos de la vida diaria y social. Este arte rupestre se sitúa en espacios transitados cotidianamente, se le ve y se le reconoce marcando cierto dominio y orden sobre esa vida diaria.

Lo destacable de esta forma de ejercer un dominio es que parece ocurrir un proceso similar sobre otros soportes materiales. El Inka parece intervenir así en las formas arquitectónicas (Adán y Uribe 1999), en las formas de las vasijas cerámicas (Cornejo 2001), en las formas de enterratorios, como en el caso del Cementerio de los Abuelos de Caspana (Ayala et al. 1999). Las diferentes manifestaciones materiales de la cuenca del río Salado, a partir de la llegada del Inka en la región, muestran así una combinación de rasgos incaicos, con otros dichos locales, que medidos en término de exclusividad e inclusividad de rasgos permiten reconocer un diálogo entre nuevos principios y la respuesta generada por las comunidades locales. Lejos de observarse un proceso de imposición violenta por parte del Inka, se reconoce un nuevo conjunto artefactual, en el cual las poblaciones locales son sujetos activos y reacomodan lo incaico.

$\mathrm{Al}$ intervenir en las diferentes formas de las expresiones materiales de las comunidades del Loa Superior, se visualiza en ese proceso el ejercicio de un poder simbólico, definido por la necesidad de ordenar y estructurar la vida social (Bourdieu 1977). Se propone, entonces, a modo de hipótesis, que la imagen rupestre formaría también parte de las estrategias de legitimación de poder e ideología Inka en el Loa Superior.

Agradecimientos: Este trabajo es extracto de la memoria de título de la autora (Sepúlveda 2002). Sin embargo, en la presentación de este estudio se agradece a Francisco Gallardo y Carole Sinclaire, por su impulso en la realización de mis trabajos en la cuenca del río Salado, por su constante apoyo y comentarios críticos. A Mauricio Uribe por guiarme en este particular acercamiento al Inka. A José Berenguer por permitirme usar los materiales de sus publicaciones. A Álvaro Romero por la revisión de este manuscrito y sus precisos comentarios. A Flavia Morello por su ayuda en la traducción del resumen que inicia este trabajo.

\section{Referencias Citadas}

Adán, L.

1999 Aquellos antiguos edificios. Acercamiento arqueológico a la arquitectura prehispánica tardía de Caspana. Estudios Atacameños 18:13-33.

Adán, L. y M. Uribe

1999 El Inka en la localidad de Caspana: un acercamiento al pensamiento político andino (río Loa, Norte de Chile). Manuscrito en posesión de los autores.

Aldunate, $\mathrm{C}$.

1993 Arqueología del Pukara de Turi. Actas del XII Congreso Nacional de Arqueología Chilena: 61-77. Boletín del Museo Regional de La Araucanía 4, Temuco.

2001 El Inka en Tarapacá y Atacama: Atacama y el recurso minero. En Tras la Huella del Inka en Chile, editado por C. Aldunate y L. Cornejo, pp. 27-33. Museo Chileno de Arte Precolombino, Santiago.

Aschero, C.

2000 Figuras humanas, camélidos y espacios en la interacción circumpuneña. En Arte en las Rocas. Arte Rupestre,
Menhires y Piedras de Colores en Argentina, editado por M. M. Podestá y M. de Hoyos, pp. 15-44. Buenos Aires. Ayala, P., O. Reyes y M. Uribe

1999 El cementerio de los Abuelos de Caspana: el espacio mortuorio local durante el dominio del Tawantinsuyu. Estudios Atacameños 18:34-53.

Bauer, B.

1992 The development of the Inca State. Segunda edición, University of Texas, Texas.

1996 Legitimization of the state in inca myth and ritual. American Anthropologist 98:327-337.

Berenguer, J.

1994 Recientes hallazgos de evidencias inkaicas en el Sector Santa Bárbara, Alto Loa. Boletín de la Sociedad Chilena de Arqueología 18:10-16, Santiago.

1999 El evanescente lenguaje del arte rupestre en los Andes atacameños. En Arte Rupestre en los Andes de Capricornio, editado por J. Berenguer y F. Gallardo, pp. 9-56. Museo Chileno de Arte Precolombino, Santiago. 
2002 Caravan Traffic, Interregional Interaction and Culture change in the Late Prehistory of Atacama Desert. Ph.D. Dissertation, University of Illinois at Urbana-Champaign. Berenguer, J., V. Castro, C. Aldunate, C. Sinclaire y L. Cornejo 1986 Secuencia del arte rupestre en el Alto Loa: una hipótesis de trabajo. En Estudios en Arte Rupestre-Primeras jornadas de Arte y Arqueología-, editado por C. Aldunate, J. Berenguer y V. Castro, pp. 87-108. Museo Chileno de Arte Precolombino, Santiago.

Berger, J.

1975 Modos de Ver. Editorial Gustavo Gili S.A., Barcelona.

Bourdieu, P.

1977 Sur le pouvoir symbolique. Annales 3:405-411.

Cáceres, I. y J. Berenguer

1996 El caserío de Santa Bárbara 41, su relación con la w’aka de Taira, Alto Loa. Chungara 28 (1-2):381-394.

Castro, V. y F. Gallardo

1995-96 El Poder de los Gentiles, Arte Rupestre en el río Salado (Desierto de Atacama). Revista Chilena de Antropología 13:79-98.

Cornejo, L.

1995 Inca en la región del río Loa: lo local y lo foráneo. Actas del XIII Congreso Nacional de Arqueología: 203213. Hombre y Desierto 9, Antofagasta.

1999 Los Incas y la construcción del espacio en Turi. Estudios Atacameños 18:165-175.

2001 Alfarería y política. En Tras la Huella del Inka en Chi$l e$, editado por C. Aldunate y L. Cornejo, pp. 114-121. Museo Chileno de Arte Precolombino, Santiago.

D'Altroy, T.

1992 Provincial Power in the Inka Empire. Smithsonian Institution Press, Washington D.C.

2003 The Incas. Blackwell publishing, United Kingdom.

DeMarrais, E., L.J. Castillo y T. Earle

1996 Ideology, materialization, and power strategies. Current Anthropology 17:15-31.

Flores Ochoa, J., K. Mac Quarie y J. Portús

1995 Oro de los Andes: las Llamas, Alpacas, Vicuñas y Guanacos de Sudamérica. Ediciones Jordi Blassi, Barcelona.

Gallardo, F.

2001 Arte rupestre y emplazamiento durante el Formativo Temprano en la cuenca del río Salado (desierto de Atacama, norte de Chile). Boletín del Museo Chileno de Arte Precolombino 8:83-98.

Gallardo, F. y F. Vilches

1995 Nota acerca de los estilos de Arte rupestre en el Pukara de Turi (Norte de Chile). Boletín de la Sociedad Chilena de Arqueología 20:26-28.

2001 Arte rupestre en la época de dominación Inka en el norte de Chile. En Tras la Huella del Inka en Chile, editado por C. Aldunate y L. Cornejo, pp. 34-37. Museo Chileno de Arte Precolombino, Santiago.

Gallardo, F., V. Castro y P. Miranda

1990 Jinetes sagrados en el desierto de Atacama: un estudio de arte rupestre andino. Boletín del Museo Chileno de Arte Precolombino 4:27-56.

Gallardo, F., C. Sinclaire y C. Silva

1999 Arte rupestre, emplazamiento y paisaje en la Cordillera del Desierto de Atacama. En Arte Rupestre en los Andes del Capricornio, editado por J. Berenguer y F. Gallardo, pp. 5796. Museo Chileno de Arte Precolombino, Santiago.
Gallardo, F., M. Uribe y P. Ayala

1995 Arquitectura Inka y poder en el Pukara de Turi, Norte de Chile. Gaceta Arqueológica Andina 24:151-171.

Gombrich, E.H.

1992 La Imagen y el Ojo: Nuevos Estudios sobre la Sicología de la Representación Pictórica. Editorial Alianza Forma, Madrid.

Horta, E.

2001 Sectorización de estilos en el arte rupestre del Loa, norte de Chile. En Estudios en Arte Rupestre -Segundas jornadas de Arte y Arqueología-, editado por J. Berenguer, L. Cornejo, F. Gallardo y C. Sinclaire, pp. 85-108. Museo Chileno de Arte Precolombino, Santiago.

Hyslop, J.

1993 Factors influencing the transmission and distribution of inka cultural materials throughout Tawantinsuyu. Latin American horizons. A symposium at Dumbarton Oaks, editado por Don St. Rice, pp. 337-356. Dumbarton Oaks Research Library and Collections, Washington D.C.

Llagostera, A.

1976 Hipótesis sobre la expansión incaica en la vertiente occidental de los Andes meridionales. En Homenaje al Dr. Gustavo Le Paige, S.J., editado por H. Niemeyer, pp. 203218. Universidad del Norte, Antofagasta.

Montt, I.

2004 Elementos de atuendo e imagen rupestre en la subregión del río Salado, Norte Grande de Chile. Actas del XV Congreso Nacional de Arqueología Chilena, Chungara Revista de Antropología Chilena Volumen Especial: 651-661.

Morris, C.

1995 Symbols to power: styles and media in the inka state. En Style, Society and Person (Archaeological and Ethnological), editado por Ch. Carr y Jill E. Neitzel, pp. 419433. Plenum Press, New York.

Rivera, M. y B. Marinov

2001 Arte rupestre y arqueología del sitio Laguna Este, alto río Loa, norte de Chile. En Estudios en Arte Rupestre -Segundas jornadas de Arte y Arqueología-, editado por J. Berenguer, L. Cornejo, F. Gallardo y C. Sinclaire, pp. 115133. Museo Chileno de Arte Precolombino, Santiago.

Salazar, D.

2002 Introducción a la Minería Prehispánica. El Complejo Minero San José del Abra, II región, 1.450-1.536 d.C. Memoria para optar al Grado de Magíster en Arqueología, Escuela de Postgrado de Arqueología, Universidad de Chile, Santiago.

Salazar, D., C. Jiménez y P. Corrales

2001 Minería y metalurgia: del cosmos a la tierra, de la tierra al Inka. En Tras la Huella del Inka en Chile, editado por C. Aldunate y L. Cornejo, pp. 60-71. Museo Chileno de Arte Precolombino, Santiago.

Sepúlveda, M.

2002 Imagen y Espacialidad en el Desierto de Atacama Durante los Períodos Tardíos (950- 1.550 d.C.). Memoria para optar al título de Arqueóloga, Departamento de Antropología y Arqueología, Universidad de Chile, Santiago.

Uribe, M., V. Manríquez y L. Adán

1999 El poder del Inka en Chile: aproximaciones a partir de la arqueología de Caspana (río Loa, Desierto de Atacama). 
Actas del III Congreso Chileno de Antropología: desafíos para el tercer milenio: 706- 722, Temuco.

Vilches, F.

1999 Inka Rock Art?: Minor Arts, Major Meanings. Thesis for the degree of Master of Arts, University of Maryland, Washington.
Vilches, F. y M. Uribe

1999 Grabados y pinturas del arte rupestre Tardío de Caspana. Estudios Atacameños 18:73-87. 